\title{
Progressão continuada e interdisciplinaridade
}

\section{Continued progression and interdisciplinarity}

Daniel de Brito Júnior é pós-graduando em Mestrado

Interdisciplinar em Ciências Humanas da Universidade de Santo Amaro.

Contato: britojunior2003@hotmail.com

\section{Resumo}

0 presente artigo, de cunho bibliográfico, busca analisar a progressão continuada, sistema de ensino implantado no estado de São Paulo. 0 método utilizado foi a análise bibliográfica da literatura referente ao tema e levantamento de dissertações e teses. Procuramos neste estudo verificar como a progressão continuada e interdisciplinaridade se convergem. Após apresentar brevemente o conceito de progressão continuada e interdisciplinaridade e, em seguida, alguns quesitos que dão suporte à pesquisa, tais como a necessidade de um planejamento interdisciplinar, a formação docente visando à interdisciplinaridade e à progressão continuada, embasado em Freitas (2003), apresento o conceito de avaliação, propondo sugestões de avaliação para o modelo de educação vigente. Este estudo busca também uma análise curricular interdisciplinar na qual os conteúdos devem estar atrelados ao meio em que estão inseridos a escola e os educandos.

Palavra-chave: Interdisciplinaridade. Progressão continuada. Avaliação.

\section{Abstract}

This paper, of a bibliographic nature, aims to analyze the continued progression, an education system implemented in the state of São Paulo. The method used was the bibliographical analysis of the existent literature on the subject as well as research of dissertations and theses. In 
this study, we aim to verify how the continued progression and interdisciplinarity converge. After briefly presenting the concept of continued progression and interdisciplinarity, and some aspects that support the research, such as the need for an interdisciplinarity planning, teacher training aimed at interdisciplinarity and continued progression, based on Freitas (2003), I present the evaluation concept, proposing assessment suggestions for the current education model. This study also intends to analyze an interdisciplinary curriculum, in which the content must be connected with the environment where the school and the students are inserted. Keywords: Interdisciplinarity. Continued progression. Evaluation.

\section{Introdução}

A progressão continuada, política educacional adotada no estado de São Paulo desde 1998, embasada na LDB 9394/96, vem sendo debatida por diversos pesquisadores nos últimos anos. Ao analisá-la, procuramos fazê-lo pelo viés da interdisciplinaridade, buscando investigar a necessidade de um ensino interdisciplinar na contemporaneidade, ou seja, como a escola oferta o ensino de forma complexa. Como a escola forma cidadãos complexos?

Este estudo busca analisar a maneira que se dá a avaliação no sistema de progressão continuada: acreditamos não haver um rompimento quanto ao método avaliativo do sistema de ensino seriado; continuamos a avaliar de forma cumulativa, quando deveríamos avaliar de forma diagnóstica e formativa, passando por diversos quesitos, com o intuito de aferir habilidades e competências que contribuem para a formação completa do aluno.

Quanto ao planejamento, este deve estar pautado em um objetivo, para não se tornar um improviso; mas esse objetivo tem que ser ramificado em diversas disciplinas, favorecendo a troca de conhecimentos, a interação entre disciplinas e, consequentemente, uma maior assimilação daquilo que foi planejado.

Visando analisar a formação docente, sua importância e necessidade, a respeito da influência sobre a organização escolar, bem como na forma de pensar a educação nos dias atuais, apenas uma formação interdisciplinar será capaz de apresentar avanços significativos, já que uma formação fragmentada não é eficaz para 
solucionar os problemas apresentados na educação. Sendo assim, a formação interdisciplinar torna-se indispensável.

Um dos objetivos deste estudo é analisar como, e de que forma, se dá a formação interdisciplinar, uma vez que esta interfere diretamente na prática pedagógica, pois, diante do sistema educacional vigente, o professor constrói e reorganiza seus conhecimentos e métodos.

A respeito do currículo, este deverá ser embasado em conteúdos que contemplem não somente o aluno, mas a sociedade em geral, já que o aluno colocará em prática tudo aquilo assimilado no âmbito escolar, pois a sociedade almeja e é tarefa da escola formar um cidadão crítico, ético e reflexivo.

\section{Progressão continuada}

A progressão continuada vem sendo abordada por diversos autores nas últimas décadas, dentre os quais podemos citar: Jefferson Mainardes, Luiz Carlos Freitas e Regiane Helena Bertagna. Observamos a ampliação dos debates referentes a tal política pública educacional; de fato, fazem-se necessários estudo e análise do tema, uma vez que este causa controvérsias. As ideias em torno da progressão continuada são divergentes. Políticos, educadores, pais e alunos ainda não têm um conceito exato sobre essa política, gerando distorções tanto nas escolas, em sua implantação e prática, como nas famílias, nas quais muitos acreditam ser a progressão continuada o motivo da defasagem educacional de seus filhos. Porém, não podemos creditar o sucesso ou o fracasso do sistema educacional paulista à progressão continuada. Essa política educacional está longe de ser a panaceia da educação, uma vez que ainda não está concluída e passa por mudanças e adaptações necessárias.

Acreditamos que seja necessário definir, mesmo que brevemente, o conceito de progressão continuada e algumas de suas implicações.

Prevista na Constituição de 1988, incorporada pela Lei de Diretrizes e Bases da Educação Nacional - LDB, instituída no Estado de São Paulo pelo Conselho Estadual de Educação - CEE (Deliberação n 09/97) e adotada pela Secretaria de Estado da Educação - SEE, a progressão continuada permite que a organização escolar seriada seja substituída por um ou mais ciclos de estudo. Essa medida altera radicalmente o percurso escolar e, como resultado, a forma 
pela qual os alunos nele se movimentam: se antes, ao final de cada ano letivo, aprovava-se ou reprovava-se os alunos com base no desempenho alcançado, espera-se, agora, que a escola encontre maneiras de ensinar que assegurem a efetiva aprendizagem de sua clientela e, consequentemente, seu progresso intra e interciclos. (SÃO PAULO, 1998, p. 6).

A progressão continuada vem romper com a política educacional vigente no estado de São Paulo até o final da década de 1990, que era o da escola seriada. Na escola seriada o educando ficava retido ou promovido a o final do ano letivo. Com a progressão continuada, o educando tem todo um ciclo de aprendizagem, que poderá ser de até nove anos, para seu progresso em aprendizagem, ficando retido, se necessário, somente no último ano correspondente de cada ciclo do Ensino Fundamental e no limite de três vezes.

O objetivo primário da progressão continuada é minimizar a evasão escolar e superar as taxas de retenção, evitando o desânimo e impedindo que os alunos possam se evadir do espaço escolar, o que sem dúvida prejudica a aprendizagem e gera altos custos ao sistema educacional.

\footnotetext{
Ser contra a progressão continuada é, em nosso entender, negar a evidência científica de que toda criança é capaz de aprender, se lhe forem oferecidas condições para tal; ou seja: respeito a seu ritmo de aprendizagem e a seu estilo cognitivo, bem como recursos para que interaja de modo profícuo com os conhecimentos. (SÃO PAULO, 1998, p. 2).
}

Assim, podemos afirmar que teoricamente a progressão continuada é de extrema importância para o processo de ensino aprendizagem. Na escola seriada existe um tempo-limite, um ano letivo, para que o educando possa assimilar todo o processo referente às competências e habilidades, e o docente conta com o mesmo período para colocar em prática seu método de ensino; sendo assim, o tempo é escasso, pois a aprendizagem da turma não acontece de modo uniforme, cada um tem suas facilidades, dificuldades, métodos de aprendizagens etc. 0 docente, por sua vez, torna-se incapaz de acompanhar o desenvolvimento individual, pois não há tempo suficiente para elaborar atividades individuais, avaliar de forma individual e acompanhar o progresso do educando.

Teoricamente, a progressão continuada oferece esse tempo ao docente e ao educando, pois o ensino-aprendizagem torna-se linear e contínuo, existindo a possibilidade de acompanhamento em um período letivo mais extenso. 
Nos reportamos a Mainardes (2009, p.86) para analisar a implantação da progressão continuada no estado de São Paulo: "Ausência de projetos de formação reforça a ideia de que os professores são apenas consumidores e executores de políticas, e não sujeitos e produtores das mesmas".

Na prática, tal implantação encontra obstáculos, uma vez que os docentes não participaram ativamente dos debates em torno da formulação referente ao texto da progressão continuada, tampouco em sua implantação. Desta forma, observamos uma distorção da ideia central por parte do profissional da educação devido à escassez de informações, à falta de estrutura, que é um fator importante para a implantação do projeto educacional, e à falta de divulgação à sociedade, uma vez que esta é a principal beneficiada com a redução da evasão escolar e da repetência.

Para que haja a convergência em relação à teoria e prática, é preciso que ocorram novos a debates entre a SEE-SP, profissionais da educação e a sociedade como um todo, para encurtar esse distanciamento entre teoria e prática, que ocorre no regime de progressão continuada no estado de São Paulo.

\section{Interdisciplinaridade}

A interdisciplinaridade tem como princípio a expansão de ideias e conhecimentos. Pretende colocar em prática um método com condições apropriadas para o desenvolvimento do conhecimento, por meio da integração entre as disciplinas, promovendo um ensino de formação no qual o aluno aprimora sua relação com o conhecimento e, consequentemente, levando esse aluno a pensar de forma complexa em relação ao homem e aos demais problemas sobre os quais a sociedade necessita de respostas. Fazenda nos alerta que um ensino interdisciplinar requer uma organização mútua, abrangendo alunos, professores, gestores e a comunidade escolar; essa aproximação não deve ocorrer somente entre as disciplinas, mas também entre cidadãos, conceitos, informações e metodologias. 
Segundo Alzira Lobo (2015), na Antiguidade o conhecimento não era transmitido de forma fragmentada; ou seja, a aprendizagem se dava de forma complexa, e o indivíduo tinha o conhecimento de um todo, uma vez que a sociedade apresentava problemas diversificados e necessitava de soluções amplas.

Segundo Lenoir (2005), o método interdisciplinar é antigo, o termo é recente, e a prática docente praticamente não existe. Nas últimas décadas surgiu o termo interdisciplinar; porém este já não vem sendo estudado e praticado com o devido merecimento.

A prática docente, esta praticamente não existe, salvo em raríssimas exceções. Observamos um distanciamento entre os conhecimentos; o professor muitas vezes desconhece o método interdisciplinar, não pratica e, ainda pior, defende sua área de conhecimento como sendo superior às demais disciplinas, quando deveria agregar conhecimentos para maior compreensão de conteúdos pelos alunos.

Analisando a relação método interdisciplinar e aluno, pensando numa rotina de sala de aula, verificamos a alternância de professores, com seus conteúdos delimitados. Ou seja, a cada aula, um novo professor e um novo conteúdo, conteúdo este que será retomado no dia seguinte; não existe continuidade, pois não existe projeto. Sendo assim, os alunos não conseguem relacionar em um mesmo tema os objetivos das aulas, uma vez que não foi praticada a interdisciplinaridade e o aluno ainda não possui habilidade suficiente para relacionar os conteúdos. Assim, por exemplo, quando o corpo docente desenvolve um projeto pedagógico, cada professor trabalha à sua maneira, e o aluno analisa as informações de forma fragmentada. Se é um projeto sobre água, analisa-se o tema proposto segundo a História, Geografia, Arte etc., mas dificilmente como um todo. Desta forma o conhecimento parece distante, o aluno não compreende e não relaciona a água com questões culturais, econômicas e sociais.

\section{Avaliação na progressão continuada e na interdisciplinaridade}

A avaliação sem dúvida é uma ferramenta de extrema importância no processo educacional. No sistema educacional seriado, a avaliação era o principal mecanismo de aprovação ou retenção do aluno ao final do ano letivo. Já no sistema de progressão continuada, a avaliação vem sendo utilizada para justificar a aprovação do aluno ao final do ciclo, exigência das 
instituições escolares. Mas, para o aluno, a avaliação ainda é utilizada como meio de pressioná-lo, embora a avaliação tenha como princípio aferir o nível de aprendizagem dos alunos, contribuindo para o desenvolvimento no decorrer dos estudos, de forma diagnóstica, verificando o que o educando já sabe e o que precisa aprender durante o ciclo. Não devemos utilizar o método de avaliação cumulativo, pois este serve apenas para amedrontar, intimidar e coagir.

No contexto da avaliação no sistema seriado, o professor detém o poder, pois está sob seu controle (avaliação) a retenção ou não do aluno. Já com a progressão continuada surgem modificações no intuito de avaliar, uma vez que não existe retenção ao final do ano letivo; com isso, essa avaliação pautada no poder e na somatória de pontos não faz mais sentido.

\section{(...) a avaliação de "valores e atitudes", que ocorrem cotidianamente em sala de aula e que consiste em expor o aluno a reprimendas verbais e físicas, comentários críticos e humilhação perante a classe, criticando seus valores e suas atitudes (FREITAS, 2003, p. 42).}

Segundo Freitas (2003) não existe um método único e preciso para uma avaliação plena e satisfatória, e ela ocorre em dois planos: o "formal" e o "informal". Se a avaliação se dá por meio de entregas de atividades, habilidades desenvolvidas, comprometimento com datas, participações, assiduidade, competências aprimoradas, respeito etc, tudo isso embasado nos quesitos individuais do aluno, como cultura, condição e convívio social e demais aspectos, o que faz com que o professor detenha o poder são outros fatores. Se a avaliação não é mais um instrumento exclusivo de retenção e avaliação, e sim de medida da aprendizagem, o poder (autoridade) está embasado no conhecimento do professor, ou seja, quanto maior seu conhecimento e sua capacidade de transmissão, maior será sua autoridade em sala de aula.

\footnotetext{
Muitas vezes é utilizada como punição, como forma de intimidar alunos pelo seu mau comportamento em sala de aula ou como julgamento nos conselhos de classe e série, geralmente realizados ao final de bimestres ou semestres, para apresentação de notas, faltas e pareceres sobre alunos e não como um momento de reflexão conjunta, para levantar dificuldades de alunos e professores, a fim de serem auxiliados em seu desenvolvimento (FAZENDA et al., 2007).
}

0 método de avaliação constantemente utilizado é realizado por meio de provas e exames. Como dito anteriormente, utilizado para 
cumprir determinações das instituições escolares, esse método torna-se ineficaz. A avaliação deve buscar o desenvolvimento do aluno, analisar seu crescimento, verificar o que ele aprendeu. Pela avaliação, o docente tem condições de avaliar suas práticas educacionais, tais como o planejamento, a seleção de conteúdos, a escolha do material, os objetivos etc.

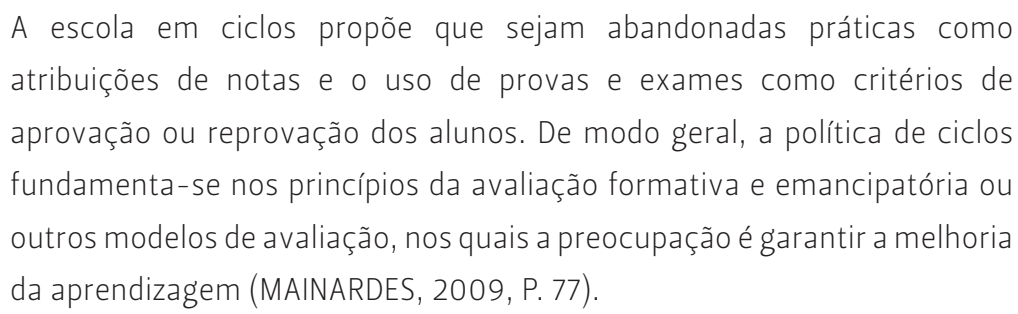

Por fim, o processo de avaliação em relação à progressão continuada e interdisciplinaridade é de fundamental importância no processo ensino-aprendizagem. Para o aluno verificamos sua evolução na aprendizagem, o que aprendeu e como poderá desfrutar do conhecimento por meio de novas metodologias aperfeiçoadas após o processo de avaliação. Para o docente, será possível verificar uma evolução no seu método de trabalho, maior segurança, pois seu trabalho está sendo aperfeiçoado.

Se a avaliação não é perfeita, somente uma avaliação interdisciplinar será capaz de contribuir com o atual modelo educacional, pois abrange aspectos além da disciplina, além da sala de aula e além da escola; ou seja, uma análise entre a escola e a sociedade na vida do aluno.

\section{Planejamento interdisciplinar}

As atividades do homem em sociedade necessitam de planejamento para uma maior possibilidade de sucesso. Quando estipulamos um ou mais objetivos necessitamos de um planejamento; caso contrário, trata-se de um improviso. No ambiente escolar não é diferente, o planejamento é de extrema importância mesmo ciente da impossibilidade de segui-lo fielmente.

É de conhecimento de todos a necessidade de uma fusão entre as disciplinas escolares, mas as dificuldades são imensas. Vão do apego a sua disciplina à falta de conhecimento em relação às demais disciplinas escolares.

Segundo Fazenda (2002), existem cinco princípios que formam 
a base da teoria interdisciplinar. São eles: humildade, coerência, espera, respeito e desapego. Não resta dúvida da importância desses quesitos. Sem eles não haveria um planejamento pedagógico interdisciplinar.

O planejamento é um processo de racionalização, organização e coordenação da ação docente, articulando a atividade escolar e a problemática do contexto social. A escola, os professores e os alunos são integrantes da dinâmica das relações sociais; tudo que acontece no meio escolar está atravessado por influências econômicas, políticas e culturais que caracterizam a sociedade de classes. Isso significa que elementos do planejamento escolar - objetivos, conteúdos, métodos - estão recheados de implicações sociais, têm o significado genuinamente político. Por essa razão, o planejamento é uma atividade de reflexão Acerca das nossas opções; se não pensamos detidamente sobre o rumo que devemos dar ao nosso trabalho ficaremos entregues aos rumos estabelecidos pelos interesses dominantes da sociedade (LIBÂNEO, 1994, p. 222).

Mainardes (2009) afirma que o professor é mero consumidor de políticas públicas educacionais.

0 professor precisa ficar vigilante para não praticar meramente as políticas de quem mal entende de educação. Durante planejamento, o docente precisa compreender sua importância na vida do aluno, na escola, na comunidade, na cultura, no crescimento do país, na formação plena do indivíduo etc. Aceitar passivamente imposições também impede o planejamento interdisciplinar.

\section{Formação docente}

A formação docente no âmbito da interdisciplinaridade exige cada vez mais discussões referentes às transformações e exigências da sociedade; esta por sua vez não é estática; também passa constantemente por mudanças, devido à evolução das tecnologias que interferem diretamente no comportamento humano e que, consequentemente, acabam por moldar a sociedade. E essa sociedade, por sua vez, vem moldar os homens.

A interdisciplinaridade no contexto da formação docente procura romper com um imaginário de formação unicamente restrito a uma determinada área de conhecimento. Se antes era o especialista em História, Geografia, Arte, Português etc, atualmente devemos agregar cada vez mais esses conhecimentos, fazendo com que eles ultrapassem o sentido teórico e façam parte 
do plano prático e com interferência na sociedade.

0 desafio da escola atualmente é romper com o ensino fragmentado. 0 aluno não adquire uma formação plena porque os professores ainda estão dentro do seu próprio nicho e criando barreiras, quando deveriam criar conexões entre as disciplinas.

\footnotetext{
[...] Por isso, entendemos o seguinte: cada disciplina precisa ser analisada não apenas no lugar que ocupa ou ocuparia na grade, mas, nos saberes que contemplam, nos conceitos enunciados e no movimento que esses saberes engendram, próprios de seu lócus de cientificidade. Essa cientificidade, então originada das disciplinas ganha status de interdisciplina no momento em que obriga o professor a rever suas práticas e a redescobrir seus talentos, no momento em que ao movimento da disciplina seu próprio movimento for incorporado (FAZENDA, 2008, p.2).
}

0 ensino interdisciplinar, ainda que nos pareça distante e difícil, pois na práxis quase não o observamos no ambiente escolar. Os professores ainda praticam a mesma metodologia do tempo em que eram discentes, ou seja, continuam limitados a sua área de conhecimento. No que se refere à gestão pedagógica, a interdisciplinaridade ainda não recebeu a devida importância; pouco se sabe, fala ou ensina sobre o tema e mesmo os projetos no interior das escolas ainda não são interdisciplinares. Por mais que exista um tema gerador, sua abordagem geralmente ainda é fragmentada. 0 aluno, devido ao baixo nível educacional, não conta com embasamento suficiente para relacionar os conteúdos.

É preciso novas atitudes de professores, gestores e alunos, um novo olhar para a educação. Sabemos da dificuldade, do esforço e do tempo que exige o trabalho docente interdisciplinar, mas somente um profissional engajado e comprometido, bem como um aluno com interesse em ascender cultural e socialmente, será capaz de evoluir para uma educação complexa.

\section{Currículo interdisciplinar}

É de conhecimento de educadores, bem como pesquisadores da área de educação e interdisciplinaridade, que a escola é o reflexo da sociedade; desta forma, o currículo obrigatoriamente deve ultrapassar a visão restrita de sala de aula. 0 conhecimento escolar tem como função primordial o desenvolvimento do ser humano, e esse desenvolvimento tem que ocorrer integralmente, pois o ser humano é complexo, ele não se encontra dividido, e sim integrado aos conhecimentos que possui, formando um ser complexo. 
0 currículo interdisciplinar exige da escola um rompimento das práticas anteriormente utilizadas em planejamentos. Ele deve contemplar uma visão complexa do entorno escolar, estar alinhado às tecnologias e comportamentos dos alunos, ser destemido etc.

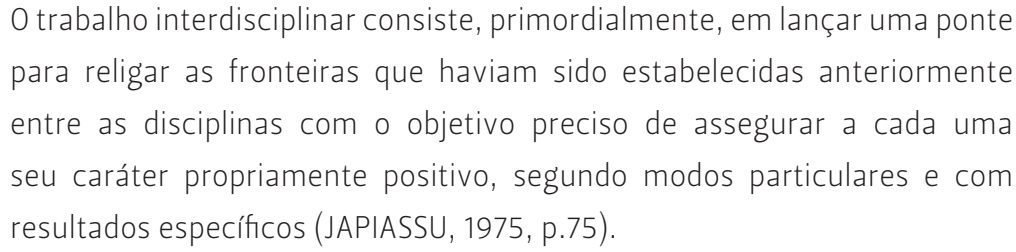

Portanto a "escola" interdisciplinar deve ser ousada. Sem a ousadia não produziremos interdisciplinaridade e continuaremos a fazer aquilo que erroneamente nos traz mais segurança.

\section{Considerações finais}

Podemos constatar, por meio deste estudo, que existe um abismo entre a teoria e a prática em relação à progressão continuada. Se, por um lado, observamos um avanço de um discurso governamental afinado, buscando apresentar resultados que mostram os avanços do sistema educacional, por outro fica nítido que não ocorreu completamente o rompimento com a educação seriada, principalmente no que se refere aos conceitos de planejamento, formação e avaliação, embora observemos um avanço superficial no quesito curricular.

Ao analisar a progressão continuada no contexto da interdisciplinaridade, verificamos que é uma prática pedagógica de extrema importância para uma formação educacional complexa, gerando resultados para toda a sociedade. Porém, a interdisciplinaridade praticamente não é colocada em prática por parte dos docentes, embora seja de conhecimento de todos que o docente não é o único responsável em inserir a interdisciplinaridade no contexto educacional.

\section{REFERÊNCIAS}

BERTAGNA, R.H. Regime de progressão continuada: limites e possibilidades. 2003. F 488. Tese (Doutorado) - Faculdade de Educação, Universidade Estadual de Campinas, UNICAMP, Campinas, 2003. 
BRANDÃO, J. (Org.) Diálogos Interdisciplinares: novos olhares nas Ciências Humanas. Embu-Guaçu: Lumen et Virtus, 2015.

JAPIASSU, H. Interdisciplinaridade e patologia do saber. Rio de Janeiro: Âmago, 1975.

FAZENDA, I.C.A. Interdisciplinaridade e transdisciplinaridade na formação de professores. In Revista Brasileira de Docência, Ensino e Pesquisa em Administração - ISSN 1984 5294 - Vol. 1, n. 1, p.24-32, maio/2009

FAZENDA, I.C.A. Interdisciplinaridade: história, teoria e pesquisa. Campinas: Papirus, 2007.

FREITAS, L.C. de. Ciclos, seriação e avaliação: confronto de lógicas. São Paulo: Editora Moderna, 2003

LENOIR, Y. Três Interpretações da perspectiva interdisciplinar em educação em função de três tradições distintas. In Revista E-Curriculum. São Paulo, v. 1, n. 1, 2005.

LIBÂNEO, J.C. Didática. São Paulo: Cortez, 2004. p. 221-247.

LUCKESI, C. Avaliação da aprendizagem escolar. São Paulo: Cortez, 1998, $7^{\text {a }}$ edição.

MAINARDES, J. A escola em ciclos: fundamentos e debates. São Paulo: Cortez, 2009

MORIN, E. (Org.). A Religação dos Saberes: o desafio do século XXI. Rio de Janeiro: Bertrand Brasil, 2001.

RAYS, O.A. Inquietações a respeito da avaliação da aprendizagem. Passo Fundo: Roteiro de Palestra, 1998.

SÃO PAULO (estado). Secretaria Estadual de Educação. Escola de Cara Nova. Planejamento 98. Progressão Continuada. São Paulo, 1998.

Recebido em: 28/09/2016

Revisto em: 07/09/2016

Aceito em: 09/12/2016

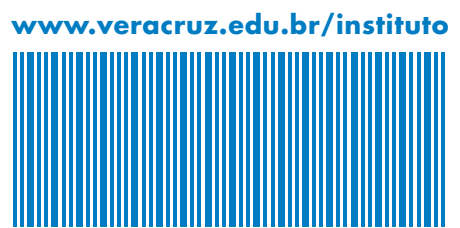

